\title{
Comentario a Alberto Vergara. Ni amnésicos ni irracionales: una mirada al electorado peruano a partir de las elecciones de 2006
}

\author{
Iván Nicolás Montes-Pastor ${ }^{1}$
}

Revista

Educación y Sociedad

Citar como: Montes-Pastor, I. N. (2021). Comentario a Alberto

Vergara. Ni amnésicos ni irracionales: una mirada al electorado peruano a partir de las elecciones de 2006. Revista Educación y Sociedad, 2(4), 6970.

https://doi.org/10.53940/reys.v2i4.76

Artículo recibido: 03-10-2021 Artículo aprobado: 27-11-2021 Arbitrado por pares

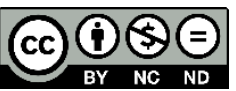

\section{ACEES}

Alberto Vergara es sin duda uno de los politólogos de vanguardia dentro del acotado campo de investigadores que alberga la ciencia política peruana. A lo largo de su obra, la pluma del autor pone en evidencia sus innegables capacidades intelectuales para conjugar o, mejor dicho, aplicar las teorías más abstractas a un caso empírico en concreto. En este análisis, Vergara toma como objeto de estudio las elecciones peruanas celebradas en el año 2006.

El libro es contundente desde el título. Así, desde el Ni amnésicos ni irracionales se propone desbaratar una moneda de ágil circulación en el sentido común del elector peruano. $Y$ es que aquella moneda que se ampara en argumentos de irracionalidad para descalificar el voto del otro no debería seguir manteniendo su troquelado dentro de la opinión pública. En efecto, la palabra irracional no es una categoría analítica por lo que el autor busca reivindicar la compresión como un método eficaz a la hora de interpretar las conductas electorales de los sujetos.

Dicho esto, Vergara cimenta su obra sobre tres grandes ejes que le permitirán hacer una especie de hermenéutica sobre el electorado peruano. El primer eje teórico es eminentemente político y se refiere a una dimensión institucional que divide el apego a la ley; y, en contraposición a la discrecionalidad. La segunda coordenada de análisis es el conocido eje económico en donde se separan dos tipos ideales: el librecambismo y el intervencionismo estatal.

Ahora bien, los dos ejes antes mencionados son una forma bastante estándar para estudiar las conductas electorales. Por este motivo, Vergara propone salir de los reduccionismos que subsumen a la política o bien dentro de la esfera económica, o más bien, dentro del restringido campo institucional. En este sentido, el autor robustece su análisis añadiendo una perspectiva que es a su vez cultural e histórica. 
¿Cómo interpretar el sentido común y el imaginario colectivo surgidos en torno a una elección?

La respuesta a esta pregunta nos lleva a mencionar el tercer eje de análisis que es decisivo para entender las fluctuaciones del electorado peruano. A saber, nos estamos refiriendo al eje que gira en torno al clivaje que distingue un horizonte estadonacional y uno posestadonacional.

Por un lado, se podría afirmar que los electores que se mueven dentro del horizonte estadonacional buscan ser incluidos en lo que representan el Estado y la nación como consecuencia de la creación de determinado aparato estatal. El deseo nacionalista es el anhelo de una ciudadanía postergada e inconclusa. Por otro lado, se encontraría otro tipo ideal de electores que son aquellos que disfrutarían de cada una de las dimensiones de la ciudadanía y que se sienten parte del proyecto estadonacional peruano. Por lo general, los electores que se encuentran en el horizonte posestadonacional votarían por candidatos con una agenda más globalista.

El libro es un armónico juego de rompecabezas en donde estas tres fichas se conjugan para brindarnos una clave de enorme utilidad para comprender cómo se articula el liderazgo, el voto y las demandas de aquella masa heterogénea que responde al nombre de pueblo. Así, el pueblo o, mejor dicho, los diferentes pueblos adoptarán conductas electorales al compás de sus necesidades correspondientes a los tres ejes expuestos.

Entonces, comprender la necesidad, la cultura y la historia nos lleva indefectiblemente a emanciparnos de los epítetos abriendo paso a un verdadero momento de entendimiento mutuo. Citando a Vergara (2019):

el problema del Perú ya no es, principalmente, el de incluir individuos al proyecto estadonacional, sino el de concluir estas inclusiones. $Y$ el elector, sostengo, decide a su candidato favorito según el grado de mayor o menor inclusión en este proyecto. (p. 84)

Dicho de otra manera, la preocupación por las necesidades de la ciudadanía no resuelta son un hilo conductor que subyace a las disquisiciones de su obra, pero también las excede 1 . En este sentido, el autor es consciente de la relevancia de su enfoque, pero a la vez reconoce que su libro no es un oráculo capaz de comprender cabalmente al elector peruano. En efecto, comprender todos los clivajes, pensamientos y motivaciones que interpelan a los electores al momento de votar es un ejercicio inasequible.

Conocer plenamente a un electorado es conocer todos los rincones del mundo. En este sentido, Vergara es el peregrino que se traslada hacia nuevos horizontes. Ni amnésicos ni irracionales se nos presenta como una brújula de tremendo valor heurístico para pensar y repensar las oscilaciones del electorado peruano.

En definitiva, la reverberación que propone Vergara en su libro pavimenta el camino para investigaciones venideras. Así, la piedra de toque que propone podría ser complementada con los nuevos clivajes y reivindicaciones sociales que marcan la tónica del pugilato político contemporáneo.

\section{Referencias}

Vergara, A. (2018). Ciudadanos sin república. De la precariedad institucional al descalabro política. Editorial Planeta.

Vergara, A. (2019). Ni amnésicos ni irracionales: Una mirada al electorado peruano a partir de las elecciones de 2006. Editorial Planeta.

\footnotetext{
${ }^{1}$ En Ciudadanos sin república, Vergara (2018) se propone resolver las cuestiones de la ciudadanía en base a la reivindicación del republicanismo como una forma de hacer política. Sin embargo, el hiato entre el ser y el deber ser republicano se mantiene presente.
} 